\title{
Recent advances in biochemical and molecular analysis of congenital adrenal hyperplasia due to 21-hydroxylase deficiency
}

Jin-Ho Choi, MD, PhD', Gu-Hwan Kim, PhD², Han-Wook Yoo, MD, PhD'

${ }^{1}$ Department of Pediatrics, ${ }^{2}$ Medical Genetics Center, Asan Medical Center, University of Ulsan College of Medicine, Seoul, Korea
Received: 3 February, 2016

Accepted: 28 February, 2016

Address for correspondence: Jin-Ho Choi, MD, PhD

Department of Pediatrics, Asan Medical Center Children's Hospital, University of Ulsan College of Medicine, 88 Olympic-ro 43-gil, Songpa-gu, Seoul 05505, Korea

Tel: +82-2-3010-3991

Fax: +82-2-473-3725

E-mail:jhc@amc.seoul.kr
The term congenital adrenal hyperplasia (CAH) covers a group of autosomal recessive disorders caused by defects in one of the steroidogenic enzymes involved in the synthesis of cortisol or aldosterone from cholesterol in the adrenal glands. Approximately $95 \%$ of all CAH cases are caused by 21 -hydroxylase deficiency encoded by the CYP21A2 gene. The disorder is categorized into classical forms, including the salt-wasting and the simple virilizing types, and nonclassical forms based on the severity of the disease. The severity of the clinical features varies according to the level of residual 21-hydroxylase activity. Newborn screening for $\mathrm{CAH}$ is performed in many countries to prevent salt-wasting crises in the neonatal period, to prevent male sex assignment in affected females, and to reduce longterm morbidities, such as short stature, gender confusion, and psychosexual disturbances. 17a-hydroxyprogesterone is a marker for 21-hydroxylase deficiency and is measured using a radioimmunoassay, an enzyme-linked immunosorbent assay, or a fluoroimmunoassay. Recently, liquid chromatography linked with tandem mass spectrometry was developed for rapid, highly specific, and sensitive analysis of multiple analytes. Urinary steroid analysis by gas chromatography mass spectrometry also provides qualitative and quantitative data on the excretion of steroid hormone metabolites. Molecular analysis of CYP21A2 is useful for genetic counseling, confirming diagnosis, and predicting prognoses. In conclusion, early detection using neonatal screening tests and treatment can prevent the worst outcomes of 21-hydroxylase deficiency.

Keywords: Congenital adrenal hyperplasia, CYP21A2, 21-Hydroxylase deficiency

\section{Introduction}

The term congenital adrenal hyperplasia $(\mathrm{CAH})$ covers a group of autosomal recessive disorders caused by a deficiency of one of the enzymes required for steroid biosynthesis in the adrenal gland ${ }^{1)}$.21-Hydroxylase deficiency (21OHD) is the most common type of CAH, accounting for approximately $95 \%$ of cases, and is caused by mutations in the CYP21A2 gene $^{2)} .21 \mathrm{OHD}$ is clinically divided into classic forms, including salt-wasting (SW) and simple virilizing (SV) forms, and nonclassic forms of disease according to disease severity ${ }^{3)}$. Most patients with classic CAH present with SW crisis or ambiguous genitalia in the neonatal period. In contrast, boys do not show ambiguous genitalia and therefore cannot be diagnosed without neonatal screening ${ }^{4)}$. Therefore, males with CAH have a higher risk of adrenal crisis in the neonatal period if they were the SW form of $21 \mathrm{OHD}^{5)}$.

The level of $17 \alpha$-hydroxyprogesterone (17OHP) is used as a marker for $21 \mathrm{OHD}$, as CAH due to $21 \mathrm{OHD}$ can be detected in newborn screening programs by measuring the amount of $17 \mathrm{OHP}$ in dried blood spots ${ }^{6}$. Newborn screening for $\mathrm{CAH}$ is now performed in many 
countries to prevent SW crises in the neonatal period, to prevent male sex assignment in affected females, and to reduce longterm morbidities, such as short stature, gender confusion, and psychosexual disturbances ${ }^{6}$.

It is critical to diagnose $21 \mathrm{OHD}$ in a timely manner and treat classic and nonclassic $\mathrm{CAH}$ to prevent adrenal crises and hyperandrogenism. This review will describe the current knowledge regarding newborn screening and biochemical and molecular genetic diagnoses of $\mathrm{CAH}$ due to $21 \mathrm{OHD}$.

\section{Newborn screening for CAH due to 210HD}

The goal of newborn screening for CAH is to detect the SW adrenal crisis; to prevent shock, brain damage, or death and begin presymptomatic treatment; and to prevent or shorten the period of incorrect gender assignment in affected females ${ }^{7,8)}$. The benefit of newborn screening is to identify boys with the SW form of CAH, as they do not have ambiguous genitalia at birth ${ }^{9}$. For effective newborn screening, a careful clinical follow-up is critical to confirm diagnosis and early treatment ${ }^{4)}$. Neonatal screening tests were first performed for congenital hypothyroidism and phenylketonuria in Korea in 1997. The measurement of 17OHP to screen for $\mathrm{CAH}$ has been included in the newborn screening program in Korea since $2006^{10}$. The incidence of $\mathrm{CAH}$ due to $21 \mathrm{OHD}$ in the Korean population detected by newborn screening is 1 in 22,700 (http://helpline. cdc.go.kr/).

The biochemical marker for the diagnosis of 21OHD is elevated 17OHP, the main substrate for the enzyme lying just upstream of the block ${ }^{4,11}$. Using filter paper cards, newborn screening programs measure 17OHP in dried blood spots obtained via a heel puncture performed between 2 and 4 days after birth ${ }^{1,12)}$. Because the circadian rhythm is influenced by cortisol $^{13)}$, an early morning $17 \mathrm{OHP}$ level is appropriate for screening $^{4)}$. The $17 \mathrm{OHP}$ level in normal newborns is $<1 \mathrm{ng} / \mathrm{mL}$ $(3 \mathrm{nmol} / \mathrm{L})^{1)}$. After the neonatal period, a cutoff value of an early morning $17 \mathrm{OHP}<0.8 \mathrm{ng} / \mathrm{mL}(2.5 \mathrm{nmol} / \mathrm{L})$ in children and $<2$ $\mathrm{ng} / \mathrm{mL}(6.0 \mathrm{nmol} / \mathrm{L})$ in adults has been suggested to exclude $\mathrm{CAH}^{14)}$. A random blood sample with 17-OHP $>100 \mathrm{ng} / \mathrm{mL}$ (300 $\mathrm{nmol} / \mathrm{L}$ ) measured by radioimmunoassay (RIA) is diagnostic of classic $21 \mathrm{OHD}$, while $1-100 \mathrm{ng} / \mathrm{mL}(30-300 \mathrm{nmol} / \mathrm{L})$ in adults indicates nonclassic $21 \mathrm{OHD}^{2}$. In menstruating women, the samples for 17OHP should be measured in the follicular phase, as the 17OHP level usually increases in the luteal phase in about half of normal females with a level of $>2 \mathrm{ng} / \mathrm{mL}(6.0 \mathrm{nmol} / \mathrm{L})^{15)}$.

Various techniques for measuring 17OHP are available, including RIAs, enzyme-linked immunosorbent assays, and time-resolved fluoroimmunoassays. The RIA was the first method used, but the dissociation-enhanced, lanthanide fluorescence immunoassay is now more common ${ }^{6}$. Each method has advantages and disadvantages in terms of specificity and sensitivity.

One of the disadvantages of newborn screening for $21 \mathrm{OHD}$ is the considerably high false positive rate, leading to high rate of repeated tests that cause patient distress and result in significant costs for follow-up. The false positive results are attributed to several factors, such as prematurity, sickness, stress, and low specificity of antibodies for 17OHP due to the cross-reactivity with 17-hydroxypregnenolone and immature adrenal steroid production $^{4,16-19}$.

\section{Recent advances in biochemical analysis of adrenal steroid profiles}

Primary screening results for CAH using a 17OHP assay must be confirmed by second tier tests, including biochemical or molecular genetic analyses ${ }^{6}$. In addition, because of the relatively high false positive rate of the first tier screening using immunoassays, there is a need for highly specific $17 \mathrm{OHP}$ screening methods to select patients for further diagnostic approaches.

Tandem mass spectrometry (MS/MS) has been recently developed to improve the positive predictive value and is more specific than the immunoassays ${ }^{20)}$. Second-tier strategies using MS/MS measure a ratio of $17 \mathrm{OHP}$ plus androstenedione to cortisol $^{20,21)}$. However, they are time-consuming to carry out and are not appropriate as first-tier screening methods ${ }^{20)}$.

Liquid chromatography linked with MS/MS (LC-MS/ MS) is a revolutionary method to measure steroid hormones in various body fluids to improve sensitivity and specificity in highly automated systems ${ }^{22}$. LC-MS/MS allows for rapid, targeted steroid hormone analysis of multiple analytes ${ }^{23}$. It is currently the technique of choice for confirming $\mathrm{CAH}$, as molecular genetic analysis is time-consuming and expensive ${ }^{24)}$. The issues of cross-reactivity and specificity can be alleviated by the use of LC-MS/MS ${ }^{22}$. However, the problem of false-positive results in premature or stressed newborns cannot be completely overcome simply by determining 17OHP alone. LC-MS/MS can measure 17OHP levels as well as other compounds, such as androstenedione, 11-deoxycortisol, 21-deoxycortisol, and cortiso $^{25,26)}$. The use of analyte ratios (precursor/product), such as (17OHP+21-deoxycortisol)/cortisol, can effectively decrease the possibility of the false positive results in neonates with high 17OHP levels due to stress, sickness, or prematurity ${ }^{6,27)}$. In nonclassic $\mathrm{CAH}$, analyte levels are only slightly different compared to those in healthy newborns, but analyte ratios demonstrate more pronounced alterations than analytes themselves ${ }^{6}$. Therefore, the specificity and sensitivity of LC-MS/ MS and the use of analyte ratios are expected to facilitate the diagnosis of mild, nonclassic CAH.

A urine steroid profile can be performed using a spot urine sample and is an additional CAH diagnostic tool that helps to differentiate between the different forms of $\mathrm{CAH}^{28}$. Gas chromatography-mass spectrometry (GC-MS) is used for urine steroid profile analysis, which is a helpful noninvasive diagnostic test used for confirmatory diagnosis ${ }^{29)}$. As markers for $21 \mathrm{OHD}$, urinary $17 \mathrm{OHP}$ metabolites, such as $17 \alpha$-hydroxypregnanolone, pregnanetriol, and 15 $\beta, 17 \alpha$-dihydroxypregnanolone, and urinary 21-deoxycortisol metabolites, such as pregnanetriolone, have been studied using GC-MS ${ }^{25,30}$. However, both mass 
spectrometric techniques are complementary tools for diagnosing $\mathrm{CAH}$, and further study is still required to improve reproducibility between laboratories ${ }^{23)}$.

\section{Indication of cosyntropin stimulation test}

Marked elevation of $17 \mathrm{OHP}$ levels is characteristic of classic $21 \mathrm{OHD}$. However, equivocal values of $17 \mathrm{OHP}$ cannot distinguish nonclassic CAH from heterozygous carriers ${ }^{31)}$ and require dynamic testing with corticotropin (cosyntropin) stimulation ${ }^{2)}$. This test is the gold standard for diagnosing nonclassic $\mathrm{CAH}^{4)}$. The cosyntropin stimulation test is performed by intravenously injecting cosyntropin at a dose of $0.25 \mathrm{mg}$ and measuring baseline and stimulated levels of $17 \mathrm{OHP}^{1)}$. Blood samples are obtained at baseline and 60 minutes after the administration of cosyntropin. Cortisol levels should also be measured at baseline and 60 minutes to measure the cortisol level. A basal $17 \mathrm{OHP}>5 \mathrm{ng} / \mathrm{mL}(15 \mathrm{nmol} / \mathrm{L})$ and $/$ or peak $17 \mathrm{OHP}>10 \mathrm{ng} / \mathrm{mL}(30 \mathrm{nmol} / \mathrm{L})$ traditionally indicates nonclassic $\mathrm{CAH}^{32)}$.

\section{Genetics of 210HD}

The CYP21A2 gene encodes 21-hydroxylase and requires electrons transferred from NADPH via the electron donor enzyme P450 oxidoreductase. This gene is located in the HLA class III region between the HLA-B and HLA-DR chromosome $6 \mathrm{p} 21.3^{1)}$. This is a highly complicated region including a highly homologous pseudogene, $C Y P 21 A 1 P^{1)}$. The functional gene (CYP21A2) and a nonfunctional pseudogene (CYP21A1P) are located closely adjacent to each other in tandem arrangement with the $C 4 A$ and $C 4 B$ genes encoding for the fourth component of the serum complement. Moreover, these units are located between a telomeric $R P$ gene and a centromeric TNX gene, comprising the RCCX modules (RP-C4-CYP21-TNX) $(\text { Fig. } 1)^{33)}$. These genes are located in tandem and in an array (C4A, CYP21A1P, TNXA, C4B, CYP21A2, and TNXB). Genes $C 4 A, C 4 B, C Y P 21 A 2$, and TNXB all encode functional proteins, while CYP21A1P, TNXA, and RP2 genes are pseudogenes that do not encode proteins ${ }^{34)}$.

The RCCX module shows high homology between the functional genes and the corresponding pseudogenes, leading to a wide variety of genetic rearrangement by unequal crossing over events, such as duplications, deletions, and fusions of the RCCX module ${ }^{1,35)}$.

To date, more than 200 CYP21A2 mutations have been discovered (http://www.hgmd.cf.ac.uk), and about 10 common mutations account for approximately $90 \%$ of cases ${ }^{4)}$. More than $90 \%$ of CYP21A2 gene mutations are caused by gene conversion or unequal crossing over ${ }^{36-38)}$. Approximately $70 \%-75 \%$ of $21 \mathrm{OHD}$ cases are the result of the microconversion of the mutations in CYP21A $1 P$ to CYP21A2 $2^{1,39)}$. About $20 \%$ are caused by unequal crossing over during meiosis, resulting in the deletion of a $30-\mathrm{kb}$ gene segment ${ }^{38)}$, encompassing the $3^{\prime}$ end of the CYP21A1P, all of the adjacent $C 4 B$, and the $5^{\prime}$ end of $C Y P 21 A 2$, producing the nonfunctioning chimeric CYP21A1P/ CYP21A2 and chimeric TNXA/TNXB genes ${ }^{33)}$. The remaining $1 \%-2 \%$ of affected alleles are spontaneous mutations not carried by either parent ${ }^{40)}$.

\section{Molecular analysis of the CYP21A2 gene}

The genetic diagnosis of patients with 210HD is not straightforward. However, it is a useful adjunct to hormonal measurements in the genetic counseling of parents upon the birth of a CAH child and of adolescents during the transition to adult care ${ }^{2)}$. Therefore, molecular diagnosis of CYP21A2 mutations is recommended for genetic counseling and confirming the diagnosis in patients with the nonclassic form of $21 \mathrm{OHD}$ because neonatal screening may miss most cases of nonclassic $\mathrm{CAH}$ and adrenocorticotropic hormone stimulated $17 \mathrm{OHP}$ levels can be equivocal ${ }^{2,6,41)}$.

It should be stressed that molecular genetic diagnosis is more complicated for $21 \mathrm{OHD}$ than for many other monogenic disorders due to the high variability of the genomic region. This includes the coexistence of two or more mutations on the same allele or the presence of more than one CYP21/C4 repeat unit on the same chromosome. In addition, care should be taken to prevent genotyping the pseudogene because genetic results can be complicated due to the duplication, deletion, and recombination of CYP21A2 in the chromosome $6 \mathrm{q} 21.3$ region. Therefore, mutant alleles must be segregated in the parents to investigate their presence in different alleles and to verify de

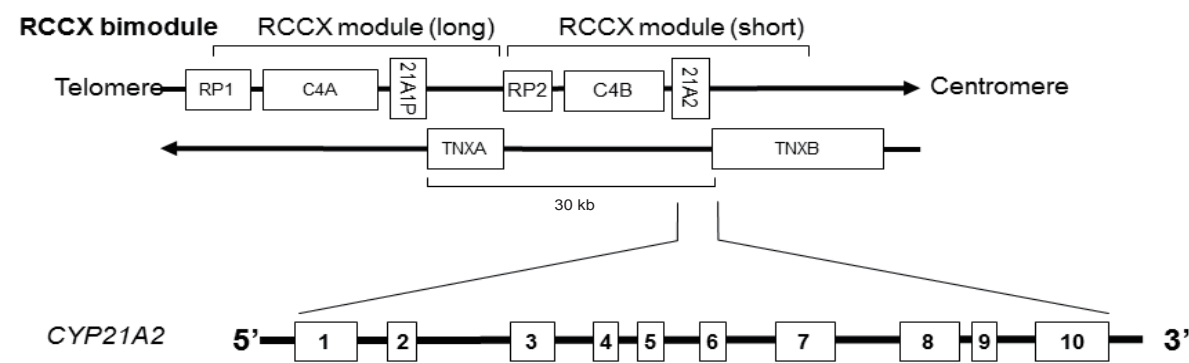

Fig. 1. Chromosomal region of $6 p 21.3$ containing the 21-hydroxylase genes representing the structure of RCCX module. 
Table 1. The mutations in CYP21A2 and their phenotypes according to their residual activities based on in vitro transfection assay

\begin{tabular}{|c|c|c|c|}
\hline & Group A & Group B & Group C \\
\hline Phenotype & Salt-wasting & Simple virilizing & Nonclassic \\
\hline In vitro activity of CYP21A2 & $0 \%-1 \%$ & $1 \%-10 \%$ & $20 \%-60 \%$ \\
\hline \multirow[t]{7}{*}{ Mutation } & Gene deletion/conversion & p.I172N & p.P30L \\
\hline & 8 bp deletion E3 & & p.V281L \\
\hline & E6 cluster & & p.P453S \\
\hline & $\mathrm{F} 306+\mathrm{t}$ & & \\
\hline & L307insT & & \\
\hline & p.Q318* & & \\
\hline & p.R356W & & \\
\hline
\end{tabular}

novo mutations ${ }^{4,42)}$.

Several strategies have been developed for molecular analysis of CYP21A2, based on polymerase chain reaction (PCR)driven amplification with allele-specific oligonucleotides to the CYP21A2 gene, followed by direct sequencing with assessment of the CYP21A2 gene copy number ${ }^{43)}$. Sanger sequencing is the gold standard for detecting point mutations and small sequence variations (indels). However, large gene rearrangements cannot be detected by direct sequencing of PCR-amplified gene fragments ${ }^{33)}$. The Southern blot method has traditionally been used to detect large gene deletions/conversions in the RCCX module. However, it is time-consuming, highly labor-intensive, and requires radioactive probes and a large amount of DNA. In addition, the Southern blot method has limitations in detecting chimeric RCCX modules, including CYP21A1P/CYP21A2 chimeric genes and TNXA/TNXB chimeric genes ${ }^{44)}$.

Therefore, alternative methods have been developed. Recently, Multiplex ligation-dependent probe amplification (MLPA) analysis for the diagnosis of $21 \mathrm{OHD}$ has been increasingly used as an easy, simple, rapid, and sensitive tool to detect deletions or duplications of the CYP21A2 gene ${ }^{45)}$. MLPA allows easy and rapid detection of gene copy number variations and the identification of chimerical genes in patients with $210 \mathrm{HD}$ without using radioactive probes ${ }^{45,46)}$ and is thought to be a valid alternative to Southern blotting ${ }^{47)}$. However, false positive results could occur because the mutations or polymorphisms very close to the probe binding regions and the ligation site may prevent probe hybridization and ligation ${ }^{47}$.

\section{Prediction of clinical phenotype according to genotype}

There is a wide spectrum of clinical features according to the type of mutations in CYP21A2. Depending on the residual activity of the mutation based on in vitro mutagenesis and expression studies, there is a good correlation between genotype and phenotype ${ }^{40)}$. CYP21A2 mutations can be classified into 3 categories (A, B, C) according to the level of enzymatic activity predicted by in vitro transfection studies (Table 1$)^{1,33,40)}$. Group A consists of mutations such as deletions or nonsense mutations that totally ablate enzyme activity; these are most often associated with the severely affected SW form. Group B consists of the missense mutations, such as p.I172N, with $1 \%-2 \%$ of normal enzyme activity. These mutations are characteristically found in patients with the SV form. Group C includes mutations such as p.V281L and p.P30L that produce enzymes retaining $20 \%-60 \%$ of normal activity; these mutations are associated with mild, nonclassic $\mathrm{CAH}^{1,40)}$.

Therefore, genotyping provides valuable diagnostic information by predicting of the clinical course of disease, and severe complications can be prevented, particularly in adults ${ }^{1,4,40)}$. Approximately $65 \%-75 \%$ of $\mathrm{CAH}$ patients are compound heterozygotes with disease-causing mutations. Compound heterozygotes with two different CYP21A2 mutations usually have a phenotype compatible with the presence of the greater residual activity ${ }^{40)}$.

\section{Conclusions}

Early diagnosis of classic CAH is critical to save lives, and diagnosing nonclassic $\mathrm{CAH}$ is important to prevent unnecessary suffering. A baseline measurement of 17OHP levels can be used for screening and diagnosis of $210 \mathrm{HD}$. LC-MS/MS and GC-MS have recently been developed as highly sensitive and specific methods for targeted steroid hormone analysis. The detection of CYP21A2 mutations is important for clinical diagnosis because there is a high variability in $17 \mathrm{OHP}$ levels. Molecular genetic analysis of CYP21A2 is useful in confirming the diagnosis, providing genetic counseling, and predicting prognoses. Genotype is well correlated with the clinical severity of $210 \mathrm{HD}$. However, further research is needed to identify modifier genes in $21 \mathrm{OHD}$, which could explain the phenotypic variability of androgen effects.

\section{Conflict of interest}

No potential conflict of interest relevant to this article was reported.

\section{References}

1. Speiser PW, White PC. Congenital adrenal hyperplasia. N Engl J Med 2003;349:776-88.

2. Speiser PW, Azziz R, Baskin LS, Ghizzoni L, Hensle TW, 
Merke DP, et al. Congenital adrenal hyperplasia due to steroid 21-hydroxylase deficiency: an Endocrine Society clinical practice guideline. J Clin Endocrinol Metab 2010;95:4133-60.

3. New MI. An update of congenital adrenal hyperplasia. Ann N Y Acad Sci 2004;1038:14-43.

4. Falhammar H, Wedell A, Nordenstrom A. Biochemical and genetic diagnosis of 21-hydroxylase deficiency. Endocrine 2015;50:306-14.

5. Falhammar H, Thoren M. Clinical outcomes in the management of congenital adrenal hyperplasia. Endocrine 2012;41:355-73.

6. White PC. Neonatal screening for congenital adrenal hyperplasia. Nat Rev Endocrinol 2009;5:490-8.

7. Cavarzere P, Camilot M, Teofoli F, Tato L. Neonatal screening for congenital adrenal hyperplasia in NorthEastern Italy: a report three years into the program. Horm Res 2005;63:180-6.

8. Thil'en A, Nordenstrom A, Hagenfeldt L, von Dobeln U, Guthenberg C, Larsson A. Benefits of neonatal screening for congenital adrenal hyperplasia (21-hydroxylase deficiency) in Sweden. Pediatrics 1998;101:E11.

9. Gidlof S, Falhammar H, Thilen A, von Dobeln U, Ritzen M, Wedell A, et al. One hundred years of congenital adrenal hyperplasia in Sweden: a retrospective, population-based cohort study. Lancet Diabetes Endocrinol 2013;1:35-42.

10. Lee DH. The prevalence of pediatric endocrine and metabolic diseases in Korea. Korean J Pediatr 2008;51:55963.

11. White PC, Speiser PW. Congenital adrenal hyperplasia due to 21-hydroxylase deficiency. Endocr Rev 2000;21:245-91.

12. White PC. Optimizing newborn screening for congenital adrenal hyperplasia. J Pediatr 2013;163:10-2.

13. Gutai JP, Meyer WJ 3rd, Kowarski AA, Migeon CJ. Twentyfour hour integrated concentrations of progesterone, 17-hydroxyprogesterone and cortisol in normal male subjects. J Clin Endocrinol Metab 1977;44:116-20.

14. Merke DP, Bornstein SR. Congenital adrenal hyperplasia. Lancet 2005;365:2125-36.

15. Azziz R, Hincapie LA, Knochenhauer ES, Dewailly D, Fox L, Boots LR. Screening for 21-hydroxylase-deficient nonclassic adrenal hyperplasia among hyperandrogenic women: a prospective study. Fertil Steril 1999;72:915-25.

16. al Saedi S, Dean H, Dent W, Stockl E, Cronin C. Screening for congenital adrenal hyperplasia: the Delfia Screening Test overestimates serum 17-hydroxyprogesterone in preterm infants. Pediatrics 1996;97:100-2.

17. Honour JW, Rumsby G. Problems in diagnosis and management of congenital adrenal hyperplasia due to 21-hydroxylase deficiency. J Steroid Biochem Mol Biol 1993;45:69-74.

18. Riepe FG, Sippell WG. Recent advances in diagnosis, treatment, and outcome of congenital adrenal hyperplasia due to 21-hydroxylase deficiency. Rev Endocr Metab Disord 2007;8:349-63.
19. Nordenström A, Wedell A, Hagenfeldt L, Marcus C, Larsson A. Neonatal screening for congenital adrenal hyperplasia: 17-hydroxyprogesterone levels and CYP21 genotypes in preterm infants. Pediatrics 2001;108:E68.

20. Minutti CZ, Lacey JM, Magera MJ, Hahn SH, McCann M, Schulze A, et al. Steroid profiling by tandem mass spectrometry improves the positive predictive value of newborn screening for congenital adrenal hyperplasia. J Clin Endocrinol Metab 2004;89:3687-93.

21. Rossi C, Calton L, Hammond G, Brown HA, Wallace AM, Sacchetta P, et al. Serum steroid profiling for congenital adrenal hyperplasia using liquid chromatography-tandem mass spectrometry. Clin Chim Acta 2010;411:222-8.

22. Stanczyk FZ, Clarke NJ. Advantages and challenges of mass spectrometry assays for steroid hormones. J Steroid Biochem Mol Biol 2010;121:491-5.

23. Kamrath C, Wudy SA, Krone N. Steroid biochemistry. Endocr Dev 2014;27:41-52.

24. Wooding KM, Auchus RJ. Mass spectrometry theory and application to adrenal diseases. Mol Cell Endocrinol 2013;371:201-7.

25. Caulfield MP, Lynn T, Gottschalk ME, Jones KL, Taylor NF, Malunowicz EM, et al. The diagnosis of congenital adrenal hyperplasia in the newborn by gas chromatography/mass spectrometry analysis of random urine specimens. J Clin Endocrinol Metab 2002;87:3682-90.

26. Kao PC, Machacek DA, Magera MJ, Lacey JM, Rinaldo P. Diagnosis of adrenal cortical dysfunction by liquid chromatography-tandem mass spectrometry. Ann Clin Lab Sci 2001;31:199-204.

27. Speiser PW. Improving neonatal screening for congenital adrenal hyperplasia. J Clin Endocrinol Metab 2004;89: 3685-6.

28. Krone N, Hughes BA, Lavery GG, Stewart PM, Arlt W, Shackleton CH. Gas chromatography/mass spectrometry (GC/MS) remains a pre-eminent discovery tool in clinical steroid investigations even in the era of fast liquid chromatography tandem mass spectrometry (LC/MS/MS). J Steroid Biochem Mol Biol 2010;121:496-504.

29. Kamrath C, Hartmann MF, Boettcher C, Zimmer KP, Wudy SA. Diagnosis of 21-hydroxylase deficiency by urinary metabolite ratios using gas chromatography-mass spectrometry analysis: Reference values for neonates and infants. J Steroid Biochem Mol Biol 2016;156:10-6.

30. Homma K, Hasegawa T, Takeshita E, Watanabe K, Anzo $\mathrm{M}$, Toyoura T, et al. Elevated urine pregnanetriolone definitively establishes the diagnosis of classical 21-hydroxylase deficiency in term and preterm neonates. J Clin Endocrinol Metab 2004;89:6087-91.

31. New MI, Lorenzen F, Lerner AJ, Kohn B, Oberfield SE, Pollack MS, et al. Genotyping steroid 21-hydroxylase deficiency: hormonal reference data. J Clin Endocrinol Metab 1983;57:320-6.

32. Bachega TA, Billerbeck AE, Marcondes JA, Madureira G, Arnhold IJ, Mendonca BB. Influence of different 
genotypes on 17-hydroxyprogesterone levels in patients with nonclassical congenital adrenal hyperplasia due to 21-hydroxylase deficiency. Clin Endocrinol (Oxf) 2000;52:601-7.

33. Krone N, Arlt W. Genetics of congenital adrenal hyperplasia. Best Pract Res Clin Endocrinol Metab 2009;23:181-92.

34. Miller WL. Clinical review 54: genetics, diagnosis, and management of 21-hydroxylase deficiency. J Clin Endocrinol Metab 1994;78:241-6.

35. Yang Z, Mendoza AR, Welch TR, Zipf WB, Yu CY. Modular variations of the human major histocompatibility complex class III genes for serine/threonine kinase RP, complement component C4, steroid 21-hydroxylase CYP21, and tenascin TNX (the RCCX module). A mechanism for gene deletions and disease associations. J Biol Chem 1999;274:12147-56.

36. White PC, Tusie-Luna MT, New MI, Speiser PW. Mutations in steroid 21-hydroxylase (CYP21). Hum Mutat 1994;3:373-8.

37. Higashi Y, Tanae A, Inoue H, Fujii-Kuriyama Y. Evidence for frequent gene conversion in the steroid 21-hydroxylase P-450(C21) gene: implications for steroid 21-hydroxylase deficiency. Am J Hum Genet 1988;42:17-25.

38. White PC, Vitek A, Dupont B, New MI. Characterization of frequent deletions causing steroid 21-hydroxylase deficiency. Proc Natl Acad Sci U S A 1988;85:4436-40.

39. Morel Y, Andre J, Uring-Lambert B, Hauptmann G, Betuel $\mathrm{H}$, Tossi $\mathrm{M}$, et al. Rearrangements and point mutations of P450c21 genes are distinguished by five restriction endonuclease haplotypes identified by a new probing strategy in 57 families with congenital adrenal hyperplasia. J Clin Invest 1989;83:527-36.

40. Speiser PW, Dupont J, Zhu D, Serrat J, Buegeleisen M, TusieLuna MT, et al. Disease expression and molecular genotype in congenital adrenal hyperplasia due to 21-hydroxylase deficiency. J Clin Invest 1992;90:584-95.

41. Gidlof S, Wedell A, Guthenberg C, von Dobeln U, Nordenstrom A. Nationwide neonatal screening for congenital adrenal hyperplasia in sweden: a 26-year longitudinal prospective population-based study. JAMA Pediatr 2014; 168:567-74.

42. Forest MG. Recent advances in the diagnosis and management of congenital adrenal hyperplasia due to 21-hydroxylase deficiency. Hum Reprod Update 2004;10:469-85.

43. Wedell A, Luthman H. Steroid 21-hydroxylase deficiency: two additional mutations in salt-wasting disease and rapid screening of disease-causing mutations. Hum Mol Genet 1993;2:499-504.

44. Lee HH, Lee YJ, Chao MC. Comparing the Southern blot method and polymerase chain reaction product analysis for chimeric RCCX detection in CYP21A2 deficiency. Anal Biochem 2010;399:293-8.

45. Concolino P, Mello E, Toscano V, Ameglio F, Zuppi C, Capoluongo E. Multiplex ligation-dependent probe amplification (MLPA) assay for the detection of CYP21A2 gene deletions/duplications in congenital adrenal hyperplasia: first technical report. Clin Chim Acta 2009;402:164-70.

46. Choi JH, Jin HY, Lee BH, Ko JM, Lee JJ, Kim GH, et al. Clinical phenotype and mutation spectrum of the CYP21A2 gene in patients with steroid 21-hydroxylase deficiency. Exp Clin Endocrinol Diabetes 2012;120:23-7.

47. Concolino P, Mello E, Minucci A, Zuppi C, Capoluongo E. Multiplex ligation-dependent probe amplification analysis is useful for diagnosing congenital adrenal hyperplasia but requires a deep knowledge of CYP21A2 genetics. Clin Chem 2011;57:1079-80. 